\title{
BMJ Open The association between cigarette smoking, cancer screening, and cancer stage: a prospective study of the women's health initiative observational cohort
}

\author{
Victor A Eng (D , ${ }^{1}$ Sean P David, ${ }^{2}$ Shufeng Li, ${ }^{1}$ Mina S Ally, ${ }^{1}$ Marcia Stefanick, ${ }^{3}$ \\ Jean $\mathrm{Y} \mathrm{Tang}^{1}$
}

To cite: Eng VA, David SP, Li S, et al. The association between cigarette smoking, cancer screening, and cancer stage: a prospective study of the women's health initiative observational cohort. BMJ Open 2020;10:e037945. doi:10.1136/ bmjopen-2020-037945

- Prepublication history for this paper is available online. To view these files, please visit the journal online (http://dx.doi. org/10.1136/bmjopen-2020037945).

Received 22 February 2020 Revised 20 April 2020 Accepted 29 May 2020

Check for updates

(c) Author(s) (or their employer(s)) 2020. Re-use permitted under CC BY-NC. No commercial re-use. See rights and permissions. Published by BMJ.

${ }^{1}$ Department of Dermatology, Stanford University School of Medicine, Redwood City, California, USA

${ }^{2}$ Department of Family Medicine, University of Chicago Pritzker School of Medicine, Chicago, Illinois, USA

${ }^{3}$ Department of Medicine, Stanford University School of Medicine, Stanford, California, USA

Correspondence to Professor Jean Y Tang; tangy@stanford.edu

\section{ABSTRACT}

Objective To assess the dose-dependent relationship between smoking history and cancer screening rates or staging of cancer diagnoses.

Design Prospective, population-based cohort study. Setting Questionnaire responses from the Women's Health Initiative (WHI) Observational Study.

Participants 89058 postmenopausal women. Outcome measures Logistic regression models were used to assess the odds of obtaining breast, cervical, and colorectal cancer screening as stratified by smoking status. The odds of late-stage cancer diagnoses among patients with adequate vs inadequate screening as stratified by smoking status were also calculated. Results Of the 89058 women who participated, $52.8 \%$ were never smokers, $40.8 \%$ were former smokers, and $6.37 \%$ were current smokers. Over an average of 8.8 years of follow-up, current smokers had lower odds of obtaining breast (OR $0.55 ; 95 \% \mathrm{Cl} 0.51$ to 0.59 ), cervical (OR $0.53 ; 95 \% \mathrm{Cl} 0.47$ to 0.59 ), and colorectal cancer (OR $0.71 ; 95 \% \mathrm{Cl} 0.66$ to 0.76 ) screening compared with never smokers. Former smokers were more likely than never smokers to receive regular screening services. Failure to adhere to screening guidelines resulted in diagnoses at higher cancer stages among current smokers for breast cancer (OR 2.78; 95\% Cl 1.64 to 4.70) and colorectal cancer (OR 2.26; 95\% Cl 1.01 to 5.05).

Conclusions Active smoking is strongly associated with decreased use of cancer screening services and more advanced cancer stage at the time of diagnosis. Clinicians should emphasise the promotion of both smoking cessation and cancer screening for this high-risk group.

\section{INTRODUCTION}

Cigarette smoking is the single largest cause of cancer worldwide yet tobacco use is decreasing less rapidly in women than men, and lung cancer remains the leading cause of cancer death in women. ${ }^{2}$ Data from mostly cross-sectional studies suggest that cancer screening services are underused in women, but other studies reported no
Strengths and limitations of this study

- This study uses prospective data drawn from a national cohort of nearly 90000 postmenopausal women with 8.8 years of follow-up and annual central adjudication of cancer cases.

- There is a possibility of recall bias and social desirability bias due to the use of self-reported questionnaire responses.

- There were not enough cases of cervical cancer in the cohort to analyse the relationship between smoking status and cervical cancer. Additionally, colorectal cancer screening was classified as receiving either faecal occult blood test or endoscopy within the past 5 years.

association between smoking status and cancer screening; thus, additional research employing prospective follow-up could shed light on the relationship. ${ }^{3}$ Because cigarette smoking is associated with other lifestyle risk factors, smoking status may also be associated with later stages of cancer presentation if healthcare is underused in this population. ${ }^{4}$

The Women's Health InitiativeObservational Cohort (WHI-OS) provides a unique opportunity to examine smoking as a barrier to cancer screening in a large, national cohort of multi-ethnic postmenopausal women. The present cross-sectional study will investigate use of cancer screening by smoking status, and determine whether the stage of cancer at the time of diagnosis varies based on smoking status among a nationally representative sample of women from the WHI-OS. We hypothesise that WHI-OS participants with a history of smoking will have reduced use of cancer screening services and will have more advanced cancer stages at diagnosis. If smoking is associated with 
reduced cancer screening and more advanced cancer stages at diagnosis, then education and counselling interventions on the importance of cancer screening should be targeted to this high-risk group of individuals.

\section{METHODS}

\section{Study population-women's health initiative}

The WHI-OS recruited postmenopausal women from 40 clinical centres across the United States from 1 October 1993 to 31 December 1998. All WHI-OS participants had a physical examination at baseline and at 3 years. Longitudinal data including demographics, risk exposures, health behaviours, and medical history were prospectively collected with annual mailed questionnaires. A central coordinating centre established standardised data collection and reporting protocols for all study sites. ${ }^{5}$ For this study, women with a diagnosis of cancer before or during the first year of the study were excluded from the analysis. Participants with unstaged cancers were also excluded. The design, eligibility criteria, and recruitment methods of the WHI-OS have previously been described (National Clinical Trial identifier: NCT00000611). Data provided to the authors for the purposes of this study were completely deidentified, and thus deemed exempt from review by the Stanford Institutional Review Board.

\section{Definition of exposures}

Smoking status was defined from a self-reported questionnaire administered at study entry. Participants were classified as smokers if they answered 'Yes' to the question 'During your entire life, have you smoked at least 100 cigarettes?' Smokers were further classified as current smokers or former smokers. Current and former smokers were then classified based on frequency, amount, and duration of smoking.

\section{Definition of cases}

The primary outcome was cancer screening (yes vs no) as determined by baseline self-reported receipt of a mammogram, a Papanicolaou/'Pap' test, a faecal occult blood test (FOBT), sigmoidoscopy, or colonoscopy. Lung cancer screening using low-dose CT was not available or recommended at the time of baseline assessments, so was not available for inclusion in our analyses.

The secondary outcome was cancer stage at diagnosis as determined by the Surveillance Epidemiology and End Results (SEER) 1988 classification method. Cancer outcomes were identified by an annual self-report questionnaire and centrally adjudicated by tumour registry coders. All in situ and localised cancers were classified as early stage cancers. Regional and distant cancers were classified as late stage cancers. Although breast, colorectal, and cervical cancer are included in the screening analysis, only women diagnosed with incident breast cancer and colorectal cancer were analysed for cancer stage at presentation due to the small number of cervical cancer cases in the WHI-OS.

\section{Statistical analysis}

Independent associations between smoking status and receipt of screening were investigated using separate multivariable logistic regression analyses with $95 \%$ CIs using never smokers as the reference group within each table column. The following baseline covariates were accounted for in the statistical model: age, race or ethnicity, body mass index (BMI), education, insurance type, usual care provider visit, and family history.

For cancer staging analysis, logistic regression models included all known cancer risk factors excluding smoking. Breast cancer covariates were based on the Gail model risk factors: sociodemographic characteristics, breast biopsy, family history of breast cancer, BMI, age at first birth, number of children breastfed, parity, and insurance type. ${ }^{6}$ The colorectal model was adjusted for sociodemographic characteristics, insurance type, BMI, family history of colorectal cancer, aspirin use, and alcohol consumption. ${ }^{7}$

Smoking status ('never', 'former', 'current') was the primary exposure of interest and all other analyses were considered of secondary interest. Secondary analyses were adjusted for multiple comparisons using the Bonferroni correction method. All tests were two sided and tested at the 0.05 level of significance.

\section{RESULTS}

A total of 89058 women were included in the analysis of which 47021 were never smokers, 36360 were former smokers, and 5677 were current smokers. From study enrolment in 1993 to data retrieval in 2017, patients were followed for a median of 8.8 years. Nearly all of never smokers $(99.88 \%)$ remained never smokers, and former smokers $(98.97 \%)$ remained former smokers. $49.49 \%$ of current smokers at baseline were no longer smoking by the last data collection. There were 7054 incident cases of breast cancer, 1600 incident cases of colorectal cancer, and 61 incident cases of cervical cancer.

Table 1 shows the odds of a patient receiving a mammogram, Pap smear, or FOBT/endoscopy based on smoking status and relative to a never smoker. Current smoker status was associated with a significantly lower odd in cancer screening with mammography (OR $0.55 ; 95 \%$ CI: 0.51 to 0.59 ), Pap smear (OR 0.53 ; $95 \%$ CI: 0.47 to 0.59 ), and FOBT/endoscopy (OR 0.71; 95\% CI: 0.66 to 0.76 ). In contrast, former smokers were significantly more likely than never smokers to receive mammogram (OR 1.05; 95\% CI: 1.004 to 1.10 ) and Pap smear (OR 1.10; 95\% CI: 1.02 to 1.18 ) but not FOBT/endoscopy (OR 1.03; $95 \%$ CI: 0.99 to 1.07$)$.

A dose-dependent inverse trend between cigarettes per day and uptake of cancer screening was present among both current and former smokers. Lower odds in the receipt of mammograms is observed among former smokers who smoked at least 25 cigarettes per day (OR $0.94 ; 95 \%$ CI 0.86 to 1.01 ) compared with former smokers who smoked less than 15 cigarettes per day (OR 1.10; 
Table 1 OR and $95 \%$ Cls of reporting breast, cervical, and colorectal cancer screening by smoking status

\begin{tabular}{|c|c|c|c|}
\hline & $\begin{array}{l}\text { Mammogram within last } 2 \\
\text { years } \\
\text { OR }(95 \% \mathrm{Cl})^{*}\end{array}$ & $\begin{array}{l}\text { Pap smear within last } 3 \\
\text { years } \\
\text { OR }(95 \% \mathrm{Cl})^{\star}\end{array}$ & $\begin{array}{l}\text { FOBT/endoscopy within last } \\
5 \text { years } \\
\text { OR }(95 \% \mathrm{CI})^{\star}\end{array}$ \\
\hline \multicolumn{4}{|l|}{ Smoking status } \\
\hline Never smoker & Ref & Ref & Ref \\
\hline Current smoker & 0.55 (0.51 to 0.59$)$ & 0.53 (0.47 to 0.59$)$ & 0.71 (0.66 to 0.76$)$ \\
\hline Never smoker & Ref & Ref & Ref \\
\hline \multicolumn{4}{|l|}{ Former } \\
\hline$<15$ & $1.10(1.04$ to 1.16$)$ & $1.11(1.01$ to 1.21$)$ & 1.05 (0.998 to 1.10$)$ \\
\hline $15-24$ & 1.02 (0.95 to 1.10$)$ & 1.09 (0.97 to 1.22$)$ & 1.01 (0.95 to 1.07 ) \\
\hline $15-24$ & $0.47(0.42$ to 0.53$)$ & 0.53 (0.44 to 0.64$)$ & 0.63 (0.56 to 0.71$)$ \\
\hline$\geq 25$ & 0.49 (0.42 to 0.59$)$ & 0.37 (0.29 to 0.48$)$ & 0.65 (0.55 to 0.78$)$ \\
\hline \multicolumn{4}{|l|}{ Pack-years } \\
\hline Never smoker & Ref & Ref & Ref \\
\hline \multicolumn{4}{|l|}{ Former } \\
\hline$<20$ & 1.11 (1.05 to 1.17$)$ & 1.13 (1.03 to 1.23$)$ & 1.04 (0.99 to 1.09$)$ \\
\hline$\geq 20$ & 0.96 (0.90 to 1.02$)$ & 0.99 (0.90 to 1.10$)$ & 1.02 (0.96 to 1.08$)$ \\
\hline \multicolumn{4}{|l|}{ Current } \\
\hline $10-19$ & 1.05 (0.98 to 1.13$)$ & 1.22 (1.07 to 1.38$)$ & 1.01 (0.95 to 1.07 ) \\
\hline $20-29$ & 0.99 (0.92 to 1.06$)$ & 1.04 (0.92 to 1.16$)$ & 1.01 (0.95 to 1.07$)$ \\
\hline $30-39$ & $0.87(0.81$ to 0.93$)$ & 0.86 (0.76 to 0.96$)$ & 0.95 (0.89 to 1.02$)$ \\
\hline $40-49$ & 0.69 (0.63 to 0.75$)$ & 0.67 (0.59 to 0.76$)$ & 0.86 (0.79 to 0.93$)$ \\
\hline$\geq 50$ & 0.65 (0.56 to 0.75$)$ & 0.68 (0.55 to 0.84$)$ & 0.73 (0.64 to 0.84$)$ \\
\hline
\end{tabular}

*Multivariate-adjusted: age, ethnicity, BMI, family history of cancer, education level, annual household income, insurance, healthcare provider, marital status, alcohol Intake.

95\% CI 1.04 to 1.16$)$. There is also a reduction in the receipt of Pap smears among current smokers who smoke at least 25 cigarettes per day (OR 0.37 ; $95 \%$ CI 0.29 to $0.48)$ compared with current smokers who smoke less than 15 cigarettes per day (OR 0.58 ; $95 \%$ CI 0.5 to 0.68 ). This inverse relationship between smoking and cancer screening persists when patients are stratified by pack years. Within each stratum of smoking status ('former smoker' or 'current smoker'), patients with a smoking history of at least 20 pack years were less likely to receive cancer screening than their counterparts with a smoking history of less than 20 pack years. Combining current and former smokers, there is a sharp decrease in cancer screenings among long-term smokers with a smoking history of at least 50 years compared with never smokers: $35 \%$ lower odds of mammogram screening, $32 \%$ lower odds of Pap smear screening, and 27\% lower odds of FOBT/endoscopy screening.

The OR of being diagnosed with a late-stage cancer rather than an early-stage cancer was calculated for patients with no screening history or delinquent screening history ('Mammogram >2years ago' and 'FOBT/endoscopy $>5$ years ago') as stratified by smoking status (table 2 ). Overall, patients who never received mammograms (OR 
Table 2 ORs and $95 \% \mathrm{Cls}$ of late-stage vs early-stage breast cancer and colorectal cancer diagnoses by smoking and screening status

\begin{tabular}{|c|c|c|c|c|}
\hline \multicolumn{5}{|c|}{ Breast cancer } \\
\hline Smoking status & Mammogram ever & $\begin{array}{l}\text { Mammogram never } \\
\text { OR }(95 \% \mathrm{Cl})^{\star}\end{array}$ & $\begin{array}{l}\text { Mammogram } \leq 2 \\
\text { years ago }\end{array}$ & $\begin{array}{l}\text { Mammogram >2 years ago } \\
\text { OR }(95 \% \mathrm{Cl})^{\star}\end{array}$ \\
\hline Never & Ref & 1.59 (0.90 to 2.81$)$ & Ref & 1.32 (1.00 to 1.75$)$ \\
\hline Former & Ref & 2.49 (1.33 to 4.67$)$ & Ref & 1.27 (1.00 to 1.89 ) \\
\hline Smoking status & $\begin{array}{l}\text { FOBT/endoscopy } \\
\text { ever }\end{array}$ & $\begin{array}{l}\text { FOBT/endoscopy never } \\
\text { OR }(95 \% \mathrm{Cl}) \dagger\end{array}$ & $\begin{array}{l}\text { FOBT/endoscopy } \\
\leq 5 \text { years ago }\end{array}$ & $\begin{array}{l}\text { FOBT/endoscopy }>5 \text { years } \\
\text { ago } \\
\text { OR }(95 \% \mathrm{Cl}) \dagger\end{array}$ \\
\hline Overall & Ref & 1.20 (0.90 to 1.61$)$ & Ref & 1.05 (0.79 to 1.39$)$ \\
\hline
\end{tabular}

*Multivariate-adjusted: age, ethnicity, BMI, age at menarche, age at first birth, number of children breastfed, hormone therapy use, family history of breast cancer, history of benign breast disease, education level, annual household income, insurance, healthcare provider, alcohol intake.

†Multivariate-adjusted: age, ethnicity, BMI, family history of colorectal cancer, inflammatory bowel disease, aspirin use, education level, annual household income, insurance, healthcare provider, alcohol intake.

$2.00 ; 95 \%$ CI 1.35 to 2.94$)$ were twice as likely to be diagnosed with late-stage breast cancer compared with those who had received mammograms in the past. More specifically, diagnosis of late-stage breast cancer was significantly higher in patients with a former history (OR 2.49; $95 \%$ CI 1.33 to 4.67 ) or current history of smoking (OR 2.95; $95 \%$ CI 1.12 to 7.78). Among patients who received their last mammogram over 2 years ago, current smokers were also significantly more likely to be diagnosed with a late-stage cancer (OR 2.78; 95\% CI 1.64 to 4.70). There were no significant associations between history of cancer screening and cancer stage at diagnosis for patients who developed colorectal cancer. The one exception is current smokers who had FOBT/endoscopy performed more than 5 years ago. These patients were more than twice as likely to present with late-stage colorectal cancer (OR 2.26; 95\% CI 1.01 to 5.05 ).

\section{DISCUSSION}

The US Preventive Services Task Force (USPSTF) currently recommends biennial mammography screening for postmenopausal women up to the age of 74 years, and the American Cancer Society and American College of Physicians advise stool testing with sigmoidoscopy or colonoscopy every 5-10 years. ${ }^{8-10}$ Numerous studies have demonstrated that smoking is associated with reduced use of preventive health services: fewer health examinations, ${ }^{11}$ decreased vaccination rates, ${ }^{12}$ and lower health insurance coverage. ${ }^{13}$ Patterns of cancer screening among smokers and non-smokers have also been variable and inconsistent. While some studies have found less compliance among smokers, ${ }^{14-16}$ others were unable to find such an association. ${ }^{17-19}$

Our study confirms that active smoking is inversely related to compliance with cancer screening recommendations, and that former smokers significantly surpass never smokers in seeking breast, cervical, and colorectal screening. Using responses from the 1990-1994 National Health Interview Surveys (NHIS), a study of women aged 42-75 similarly found adjusted odds of mammography and Pap test to be higher among former smokers and lower among current smokers who smoked more than one pack per day. ${ }^{20}$ A survey of 52754 respondents aged 50 years and older also observed more FOBT or sigmoidoscopy among former smokers, while current smoking status was inversely associated with colorectal cancer screening. ${ }^{21}$ Although several studies have reported associations between smoking status and cancer screening, few have assessed this relationship in a dose-dependent manner. A national study of preventive services use had reported reduced receipt of breast, cervical, and colorectal cancer screening in daily smokers compared with non-daily smokers. ${ }^{3}$ The current study further quantifies smoking severity in additional dimensions and finds cancer screening to inversely correlate with frequency, amount, and duration of smoking.

Concern for personal health is the most common reason given for smoking cessation among former smokers and may explain why this health-conscious population seeks cancer screening more frequently than never smokers. ${ }^{22}$ On the contrary, smokers are overly optimistic about their health and consistently underestimate the magnitude of 
their cancer risk. ${ }^{23}$ This dichotomy in risk perception corresponds with our results, indicating that current smokers have the lowest rates of screening while former smokers approach and often exceed never smokers in cancer screening, which could correspond to an overall advantage in seeking other preventive health behaviours.

Independent of smoking status, late-stage breast cancer rates were moderately elevated among all patients with inadequate screening. This study's results are in concordance with published associations between screening and late-stage presentation. ${ }^{24}$ Mammograms aid in uncovering early-stage breast cancer before it progresses to more advanced cancer. ${ }^{26}$ As expected, our data demonstrate that women who refuse regular mammography screening are likely to harbour later-stage breast cancer. These latent advanced cancers go undiagnosed if patients do not present to clinic for the opportunity to be screened. Of particular interest are current smokers who have the highest rate of developing a late-stage breast cancer if screening guidelines are not followed. While the odds of late-stage breast cancer in never smokers did not vary significantly based on screening history (OR 1.59; $95 \%$ CI 0.90 to 2.81 ), active smokers with no history of mammography had a threefold increased odds of being diagnosed with a late-stage cancer (OR 2.95; 95\% CI 1.12 to 7.78). The role of cigarette smoking in the aetiology of breast cancer remains unclear-perhaps a higher risk of breast cancer could be due to less screening in addition to the genotoxic damage from smoke. ${ }^{27} 28$ Nonetheless, active smokers without recent testing fare the worst in cancer staging and deserve targeted attention to ensure timely cancer screening.

Cancer screening is found to associate less with the detection of colorectal cancer compared with breast cancer. However, unlike mammograms which detect cancerous lesions, FOBTs and endoscopies also detect precancerous adenomas in addition to cancerous polyps. Thus, a difference in the ratio of late-stage cancer vs earlystage or precancerous lesions may only become apparent among those with significant risk factors such as smoking. Thus, a significantly higher late vs early presentation for colorectal cancer was only found among current smokers and underscores the importance of regular screening in this high-risk population. Furthermore, this WHI cohort had fewer incident cases of colorectal cancer compared with breast cancer ( 1600 vs 7054 cases), thus reducing the statistical power for analyses with colorectal cancer.

The strengths of this study include the large study size, geographical diversity, and ethnic diversity of the WHI-OS participant cohort. The study also benefited from its prospective study design and regular annual adjudication of cancer events which, along with the exclusion of patients with pre-existing cancer diagnoses, mitigates concerns about reverse causation. The lengthy follow-up of 8.8 years allows us to associate lack of cancer screening with incidence of late stage cancers from the same participant cohort. Additional strengths include central adjudication of reported cancer cases and detailed information on known confounders and exposures that this study could take into account. Furthermore, this study assessed the dose-dependent association of smoking with cancer screening rates, which has not been done in many other studies.

Limitations of this study include its observational nature and its focus on postmenopausal women. Selfreported data on smoking and cancer screening may be subject to recall bias and social desirability bias. Although the validity and accuracy of self-reported smoking is thought to be high in most studies, overreporting of preventive health behaviours remains common and difficult to quantify. ${ }^{29}{ }^{30}$ Current guidelines for colorectal cancer screening recommend annual FOBT and endoscopy every 5 years. However, colorectal cancer screening was recorded in the study dataset by having had either a FOBT or an endoscopy within the past 5 years. Thus, we were unable to provide a separate analysis with shorter time intervals using annual FOBT results. Lastly, we were not able to assess the association between smoking status and cervical cancer incidence due to the small number of incident cervical cancer cases in the WHI-OS cohort.

\section{CONCLUSION}

In summary, active smoking is associated with decreased use of breast, colorectal, and cervical cancer screening services in a dose-dependent manner. Additionally, while cancer screening is important for avoiding late-stage presentation in patients of all smoking statuses, active smokers without appropriate screening have significantly higher odds of being diagnosed with an advanced breast or colorectal cancer. Patients of all smoking histories should be encouraged to receive regular mammograms and FOBT/endoscopy, particularly active smokers who are less likely to seek screening. Public health initiatives should continue the effort of encouraging smoking cessation to minimise smoking-related morbidities.

\section{Twitter Sean P David @spdavid}

Contributors VAE, SPD, MSA, MS, and JYT contributed to the study design and interpretation of data. VAE, SL, and JYT had full access to the data. SL performed the data extraction and analysis. VAE prepared the initial drafts of the manuscript with additional input from SPD, MS, and JYT. VAE and MSA designed the tables with additional input from SPD, SL, MS, and JYT. All authors contributed to the drafts and final version of the manuscript.

Funding This research was supported in part by the Stanford Medical School Medical Scholars Research Fellowship (V.E.).

Competing interests None declared.

Patient and public involvement Patients and/or the public were not involved in the design, or conduct, or reporting, or dissemination plans of this research.

Patient consent for publication Not required.

Provenance and peer review Not commissioned; externally peer reviewed.

Data availability statement Data may be obtained from a third party and are not publicly available. Data used in this study are hosted by the Women's Health Initiative and were fully deidentified and anonymised prior to receipt by the study authors. Eligible researchers may download the study protocol, study procedures, data collection forms, and deidentified participant data directly at the WHI online resource (https://www.whi.org/researchers/data/Pages/Home.aspx). Other 
researchers may download the publicly available data through BioLINCC (https:// biolincc.nhlbi.nih.gov/studies/whict).

Open access This is an open access article distributed in accordance with the Creative Commons Attribution Non Commercial (CC BY-NC 4.0) license, which permits others to distribute, remix, adapt, build upon this work non-commercially, and license their derivative works on different terms, provided the original work is properly cited, appropriate credit is given, any changes made indicated, and the use is non-commercial. See: http://creativecommons.org/licenses/by-nc/4.0/.

\section{ORCID iD}

Victor A Eng http://orcid.org/0000-0001-7045-0152

\section{REFERENCES}

1 Drope J, Schluger N, Cahn Z. The tobacco atlas. Atlanta: American Cancer Society and Vital Strategies, 2018.

2 Pirie K, Peto R, Reeves GK, et al. The 21st century hazards of smoking and benefits of stopping: a prospective study of one million women in the UK. Lancet 2013;381:133-41.

3 Vander Weg MW, Howren MB, Cai X. Use of routine clinical preventive services among daily smokers, non-daily smokers, former smokers, and never-smokers. Nicotine Tob Res 2012;14:123-30.

4 Kiefe $\mathrm{Cl}$, Williams OD, Greenlund KJ, et al. Health care access and seven-year change in cigarette smoking. The cardia study. Am J Prev Med 1998;15:146-54.

5 Langer RD, White E, Lewis CE, et al. The women's health Initiative observational study: baseline characteristics of participants and reliability of baseline measures. Ann Epidemiol 2003;13:S107-21.

6 Gail MH, Brinton LA, Byar DP, et al. Projecting individualized probabilities of developing breast cancer for white females who are being examined annually. J Natl Cancer Inst 1989;81:1879-86.

7 Edwards BK, Ward E, Kohler BA, et al. Annual report to the nation on the status of cancer, 1975-2006, featuring colorectal cancer trends and impact of interventions (risk factors, screening, and treatment) to reduce future rates. Cancer 2010;116:544-73.

8 Siu AL, U.S. Preventive Services Task Force. Screening for breast cancer: U.S. preventive services task force recommendation statement. Ann Intern Med 2016;164:279-96.

9 Smith RA, Cokkinides V, Eyre HJ. American cancer society guidelines for the early detection of cancer, 2006. CA Cancer J Clin 2006;56:11-25.

10 Wilt TJ, Harris RP, Qaseem A, et al. Screening for cancer: advice for high-value care from the American College of physicians. Ann Intern Med 2015;162:718-25.

11 Oakes TW, Friedman GD, Seltzer CC, et al. Health service utilization by smokers and nonsmokers. Med Care 1974;12:958-66.

12 Stehr-Green PA, Sprauer MA, Williams WW, et al. Predictors of vaccination behavior among persons ages 65 years and older. Am J Public Health 1990;80:1127-9.
13 Hurd MD, McGarry K. Medical insurance and the use of health care services by the elderly. J Health Econ 1997;16:129-54.

14 Fredman L, Sexton M, Cui Y, et al. Cigarette smoking, alcohol consumption, and screening mammography among women ages 50 and older. Prev Med 1999;28:407-17.

15 Lian M, Jeffe DB, Schootman M. Racial and geographic differences in mammography screening in St. Louis City: a multilevel study. J Urban Health 2008;85:677-92.

16 Carlos RC, Fendrick AM, Patterson SK, et al. Associations in breast and colon cancer screening behavior in women. Acad Radiol 2005;12:451-8.

17 Kenfield SA, Stampfer MJ, Rosner BA, et al. Smoking and smoking cessation in relation to mortality in women. JAMA 2008;299:2037.

18 Huncharek M, Haddock KS, Reid R, et al. Smoking as a risk factor for prostate cancer: a meta-analysis of 24 prospective cohort studies. Am J Public Health 2010;100:693-701.

19 Eisen SA, Waterman B, Skinner CS, Sugg Skinner C, et al. Sociodemographic and health status characteristics with prostate cancer screening in a national cohort of middle-aged male veterans. Urology 1999;53:516-22.

20 Rakowski W, Clark MA, Ehrich B. Smoking and cancer screening for women ages 42-75: associations in the 1990-1994 National health interview surveys. Prev Med 1999;29:487-95.

21 Shapiro JA, Seeff LC, Nadel MR. Colorectal cancer-screening tests and associated health behaviors. Am J Prev Med 2001;21:132-7.

22 Hyland A, Li Q, Bauer J, et al. Predictors of cessation in a cohort of current and former smokers followed over 13 years. Nicotine Tob Res 2004;6:363-9.

23 Strecher VJ, Kreuter MW, Kobrin SC. Do cigarette smokers have unrealistic perceptions of their heart attack, cancer, and stroke risks? $J$ Behav Med 1995;18:45-54.

24 Kronborg O, Fenger C, Olsen J, et al. Randomised study of screening for colorectal cancer with faecal-occult-blood test. Lancet 1996;348:1467-71.

25 Hardcastle JD, Chamberlain JO, Robinson $\mathrm{MH}$, et al. Randomised controlled trial of faecal-occult-blood screening for colorectal cancer. Lancet 1996;348:1472-7.

26 Bleyer A, Welch HG. Effect of three decades of screening mammography on breast-cancer incidence. $N$ Engl J Med 2012;367:1998-2005.

27 Terry PD, Rohan TE. Cigarette smoking and the risk of breast cancer in women: a review of the literature. Cancer Epidemiol Biomarkers Prev 2002;11:953-71.

28 Hecht SS. Tobacco smoke carcinogens and breast cancer. Environ Mol Mutagen 2002;39:119-26.

29 Patrick DL, Cheadle A, Thompson DC, et al. The validity of selfreported smoking: a review and meta-analysis. Am J Public Health 1994;84:1086-93.

30 Newell SA, Girgis A, Sanson-Fisher RW, et al. The accuracy of selfreported health behaviors and risk factors relating to cancer and cardiovascular disease in the general population: a critical review. Am J Prev Med 1999;17:211-29. 